\title{
Studies on the Absorptive Defect for Triglyceride in Abetalipoproteinemia *
}

\author{
P. O. Ways, † C. M. Parmentier, H. J. Kayden, $\$$ J. W. Jones, $§$ D. R. Saunders, $\|$ \\ AND C. E. Rubin П \\ (From the Department of Medicine, University of Washington School of Medicine, Seattle, \\ Wash., and the Department of Medicine, New York University School of \\ Medicine, Nere York, N. Y.)
}

\begin{abstract}
Summary. The nature of the gastrointestinal absorptive defect for triglyceride in three subjects with abetalipoproteinemia has been investigated by studying peroral biopsies of the gastrointestinal mucosa. The following conclusions were reached.

1) In confirmation of other studies, the abnormal vacuoles within the duodenal absorptive cells of these individuals were lipophilic.

2) On chemical analysis there was significantly more mucosal lipid than found in normal fasting specimens, and almost the entire increase was due to triglyceride.

3) This excess mucosal lipid was reduced by a low fat diet, but even after 34 days on such a diet there was still an excess of lipophilic material near the villus tip and increased quantities of total lipid and triglyceride when compared with material from normal subjects similarly treated.

4) Although there are demonstrable qualitative changes in mucosal and plasma lipids after an acute fat load, they are not quantitatively as great as in normal individuals. Fat balance studies and the qualitative changes in plasma and tissue lipids that do occur after more extended periods on different types of dietary fat do indicate that a considerable percentage of the dietary fat is assimilated. The route by which it is absorbed remains to be clarified.
\end{abstract}

\section{Introduction}

In recent years there has been increasing interest in the rare syndrome variously designated as "acanthocytosis" $(1,2)$, "abetalipoproteinemia"

\footnotetext{
* Submitted for publication February 21, 1966; accepted September 15, 1966.

This work was supported by funds from the American Heart Association, provided in part by the Washington State Heart Association, and by U. S. Public Health Service grants HE 07326, AM HD 08864, NCI-4320, and 5RO1 HE 06481.

A portion of this work was conducted through the Clinical Research facility of the University of Washington (National Institutes of Health grant FR-37).

$\dagger$ Established Investigator, American Heart Association. Address requests for reprints to Dr. Peter O. Ways, Dept. of Medicine, University of Washington School of Medicine, Seattle, Wash. 98105.

‡ Supported by U. S. Public Health Service Career Development Award K3-HE-14-828.
}

(2), the "Bassen-Kornzweig syndrome" (3), and "congenital beta lipoprotein deficiency" (4). The salient features of this disorder include an unusual morphologic abnormality of red cells (acanthocytosis), neurological disease, retinal degeneration, absence of plasma low density (beta) lipoproteins, and malabsorption.

The latter is distinguished from other malabsorption syndromes by the morphologic appearance of the small bowel mucosa: the fasting absorptive cells of the duodenum and proximal jejunum are engorged by numerous vacuoles $(2,5)$, which are

$\S$ Present address: Dept. of Medicine, Veterans Administration Hospital, Richmond, Va.

II Supported by an indirect traineeship in gastroenterology (2A-5099) from the National Institute of Arthritis and Metabolic Diseases.

I Supported by a Career Research Award (K6-3449) from the U. S. Public Health Service. 
lipophilic (4-6) but do not distort villus architecture. Any unifying pathogenesis of the malabsorption in abetalipoproteinemia must explain this morphologic abnormality as well as the absence of demonstrable postprandial chylomicronemia (2). At present, the explanation that best fits the available data is that the formation of chylomicrons by the absorptive cell, or their discharge from it, or both, are defective, and an excess of lipid is found within the cell.

This communication provides supporting evidence for this concept based on chemical and morphologic analyses of duodenal biopsies from patients on ad libitum, fat-free, and added fat diets. ${ }^{1}$

\section{Methods}

Patients, experimental design, and dietary control. $\mathrm{Pa}-$ tient 1 (C.R.) is the patient originally reported by

1 Some of these findings have been reported in abstract form (6).
Mabry, DiGeorge, and Auerbach $(5,7)$ whose blood lipids have also been studied in this laboratory (8). For the present study she was biopsied only once, in May 1960. Patient 2 (M.S.) has also been previously reported (8). For parts of this study he was hospitalized on the U. S. Public Health Service Clinical Research Center at the University of Washington Hospital. His clinical course since the previous report is described in Appendix 1. His average weight was $21 \mathrm{~kg}$ during the present experiments. Patient 3 (J. G.), heretofore unreported, is described in Appendix 2. He was also hospitalized on the University of Washington Clinical Research Center during these studies, when his weight was 17 to $21 \mathrm{~kg}$. The diagnosis of abetalipoproteinemia was established in all three cases on the basis of a typical clinical picture, characteristic duodenal biopsy, acanthocytosis, and absence of beta lipoproteins by immunoelectrophoresis.

All of the patients were studied at least once while they were consuming ad libitum diets. In Patient 1 no estimate could be obtained of dietary fat intake. Patients 2 and 3 were consuming an average of 0.86 and $0.88 \mathrm{~g}$ of fat per $\mathrm{kg}$ per day on their free choice regimens. In $\mathrm{Pa}-$

TABLE I

Lipids of the duodenojejunal mucosa in abetalipoproteinemia: patients and their family members*

\begin{tabular}{|c|c|c|c|c|c|c|c|c|c|c|c|}
\hline & \multirow{2}{*}{\multicolumn{2}{|c|}{ Normals† }} & \multicolumn{4}{|c|}{ Patients } & \multirow{2}{*}{\multicolumn{3}{|c|}{ Family of Patient 2}} & \multirow{2}{*}{\multicolumn{2}{|c|}{$\begin{array}{l}\text { Family of } \\
\text { Patient } 3\end{array}$}} \\
\hline & & & \multirow[b]{2}{*}{1} & \multicolumn{2}{|c|}{2} & \multirow[b]{2}{*}{3} & & & & & \\
\hline & Mean & $\mathrm{SD}$ & & $\mathbf{a}$ & b & & Father & Mother & Brother & Father & Sister \\
\hline $\begin{array}{l}\text { Total lipid (\% of biopsy wet weight) } \\
\text { Phospholipid (\% of lipid) } \\
\text { Cholesterol (\% of lipid) } \\
\text { Free fatty acid (\% of lipid) } \\
\text { Triglyceride (\% of lipid) } \\
\text { (\% of biopsy weight) }\end{array}$ & $\begin{array}{r}4.2 \\
49.6 \\
7.7 \\
3.2 \\
22.8 \\
1.0\end{array}$ & $\begin{array}{l}.9 \\
8.6 \\
1.9 \\
1.9 \\
8.5\end{array}$ & $\begin{array}{l}12.6 \ddagger \\
18.3 \ddagger\end{array}$ & $\begin{array}{r}14.5 \ddagger \\
9.3 \ddagger \\
2.6 \ddagger \\
77.5 \ddagger \\
11.2\end{array}$ & $\begin{array}{c}10.5 \ddagger \\
18.0 \ddagger \\
68.0 \ddagger \\
7.5\end{array}$ & $\begin{array}{c}6.0 \\
32.5 \\
7.2 \\
1.6 \\
42.0 \ddagger \\
2.5\end{array}$ & $\begin{array}{r}2.9 \\
62.5 \\
8.7\end{array}$ & $\begin{array}{r}3.8 \\
42.5 \\
8.0 \\
10.8\end{array}$ & $\begin{array}{r}3.0 \\
62.5 \\
9.2\end{array}$ & $\begin{array}{r}4.0 \\
40.0 \\
5.4 \\
4.9 \\
18.4\end{array}$ & $\begin{array}{c}4.5 \\
47.5 \\
11.8 \ddagger \\
7.7 \\
12.5\end{array}$ \\
\hline \multicolumn{12}{|l|}{$\begin{array}{l}\text { Phospholipid distribution } \\
\text { (\% of total phospholipid) }\end{array}$} \\
\hline $\begin{array}{l}\text { Lecithin } \\
\text { Sphingomyelin and PI }\end{array}$ & $\begin{array}{l}43.0 \\
16.8 \\
20.4\end{array}$ & $\begin{array}{l}3.4 \\
1.2 \\
3.1\end{array}$ & & & $\begin{array}{l}44.4 \\
15.7\end{array}$ & $\begin{array}{l}41.0 \S \\
19.1 \S\end{array}$ & $\begin{array}{l}46.4 \\
15.5\end{array}$ & $\begin{array}{l}45.5 \\
13.9 \ddagger\end{array}$ & $\begin{array}{l}45.7 \\
13.7 \ddagger\end{array}$ & $\begin{array}{l}45.9 \\
13.7 \ddagger\end{array}$ & $\begin{array}{l}41.4 \\
15.0\end{array}$ \\
\hline & 13.5 & 2.5 & & & 30.1 & $33.2 \S$ & 33.3 & 36.2 & 35.7 & 37.2 & 40.0 \\
\hline Total recovery & 105 & & & & 100 & $92 \S$ & 103 & 94 & 94 & 108 & 94 \\
\hline $\begin{array}{l}\text { Phospholipid fatty acids } \\
\text { (moles /100 moles fatty acid) } \\
16: 0 \\
18: 0 \\
18: 1 \\
18: 2 \\
20: 4\end{array}$ & $\begin{array}{r}23.9 \\
22.4 \\
16.8 \\
26.2 \\
7.6\end{array}$ & $\begin{array}{l}3.3 \\
2.3 \\
2.4 \\
3.2 \\
2.6\end{array}$ & & $\begin{array}{l}21.3 \\
18.3 \\
23.1 \ddagger \\
21.3 \\
13.5 \ddagger\end{array}$ & & $\begin{array}{l}26.0 \\
15.0 \ddagger \\
23.0 \ddagger \\
14.0 \ddagger \\
9.8\end{array}$ & & & $\begin{array}{r}19.3 \\
26.6 \\
18.2 \\
23.6 \\
7.9\end{array}$ & $\begin{array}{r}25.0 \\
19.9 \\
16.3 \\
26.7 \\
6.8\end{array}$ & $\begin{array}{l}24.5 \\
19.9 \\
15.5 \\
23.6 \\
11.4\end{array}$ \\
\hline $\begin{array}{l}\text { Triglyceride fatty acids } \\
\text { (moles/100 moles fatty acid) } \\
16: 0 \\
16: 1 \\
18: 0 \\
18: 1 \\
18: 2\end{array}$ & $\begin{array}{r}31.8 \\
3.7 \\
11.9 \\
35.3 \\
13.7\end{array}$ & $\begin{array}{l}4.4 \\
1.1 \\
1.2 \\
4.8 \\
6.2\end{array}$ & & $\begin{array}{r}25.3 \\
1.9 \\
13.9 \\
38.1 \\
10.7\end{array}$ & & $\begin{array}{c}37.0 \\
4.3 \\
15.0 \ddagger \\
33.0 \\
7.0\end{array}$ & & & & $\begin{array}{r}28.0 \\
2.9 \\
13.6 \\
38.0 \\
12.6\end{array}$ & $\begin{array}{c}27.7 \\
4.2 \\
9.0 \ddagger \\
37.4 \\
17.5\end{array}$ \\
\hline
\end{tabular}

* All biopsies obtained after an overnight fast with individuals consuming a "free choice" diet. Abbreviations: $\mathrm{PI}=$ phosphatidyl inositol, $\mathrm{PE}=$ phosphatidyl ethanolamine, and PS = phosphatidyl serine.

$\dagger$ Normal values from (11).

$\mp$ Greater than 2 SD from normal mean.

$\$$ Average of determinations on two groups of biopsies done 18 months apart. 
tients 2 and 3 the effects of safflower oil ${ }^{2}$ and corn oil ${ }^{3}$ on mucosal, plasma, and red cell lipids were studied. Patient 3 was also studied on a formula diet containing only $0.3 \mathrm{~g}$ of lipid per day. The intake of fat, both while the patients were on ad libitum and controlled fat diets, was estimated from standard tables of food composition (9). The "fat-free" formula was composed of Meritene, ${ }^{4} 160 \mathrm{~g}$; Dextromaltose no. 1, $150 \mathrm{~g}$; water, $574 \mathrm{~g}$. Each $100 \mathrm{~g}$ of Meritene contained $0.2 \mathrm{~g}$ fat, 7,000 IU vitamin A, and 550 IU vitamin $\mathrm{D}$, but no vitamin $\mathrm{E}$ or $\mathrm{K}$. On all dietary regimens patient weights were stable or increased slightly.

Chemical analyses. For analysis of stool fat, specimens were collected into refrigerated paint cans over 2to 5-day periods and frozen until analyzed. After addition of water to a total volume of $2,000 \mathrm{ml}$, the cans were sealed, shaken for 10 minutes on a mechanical paint shaker, and $10-\mathrm{ml}$ samples taken for analysis by the method of Van De Kamer, Huinink, and Weyers (10). The fat balance data in Table II exclude the first 3 days of each dietary period to allow for equilibration. The methods employed for the lipid analyses of the gastrointestinal biopsy material, methods for the emulsification of corn oil, and the data on normal individuals have been previously reported (11). Red cell and plasma lipids and plasma lipoproteins were analyzed by methods previously described $(12,13)$. Triglyceride: was measured by a modified periodate oxidation method (14).

Morphologic studies. The preparation of osmium-fixed, epon-embedded $1-\mu$ sections and their staining with toluidine blue as well as the preparation of formalin-fixed, carbowax material subsequently stained with oil red $\mathrm{O}$ have been described in detail $(15,16)$. Some fasting biopsies were quick frozen, sectioned by cryostat, and stained with oil red $\mathrm{O}$.

\section{Results}

\section{Morphology and lipid analysis on ad libitum diets}

By both light and electron microscopy (17) the particles seen in the fasting biopsies of our patients were similar to those seen during normal fat absorption $(15,16,18)$, and the lipid character of the particles was demonstrable by oil red $\mathrm{O}$ stain in the frozen sections. However, they were larger, more numerous, and not observed in the intercellular spaces or the Golgi vacuoles (17).

Analytically, total lipid was 1.5 to 3.5 times that normally found in fasting mucosal biopsies ( $\mathrm{Ta}$ ble I). Virtually all of the increase appeared to be due to triglycerides. As per cent of total lipid

\footnotetext{
2 Saffola safflower oil, Pacific Vegetable Oil Corp., San Francisco, Calif.

${ }^{3}$ Mazola corn oil, Best Foods Division of Corn Products Co., New York, N. Y.

4 D. M. Doyle Pharmaceutical Co., Division of Dietene, Minneapolis, Minn.
}

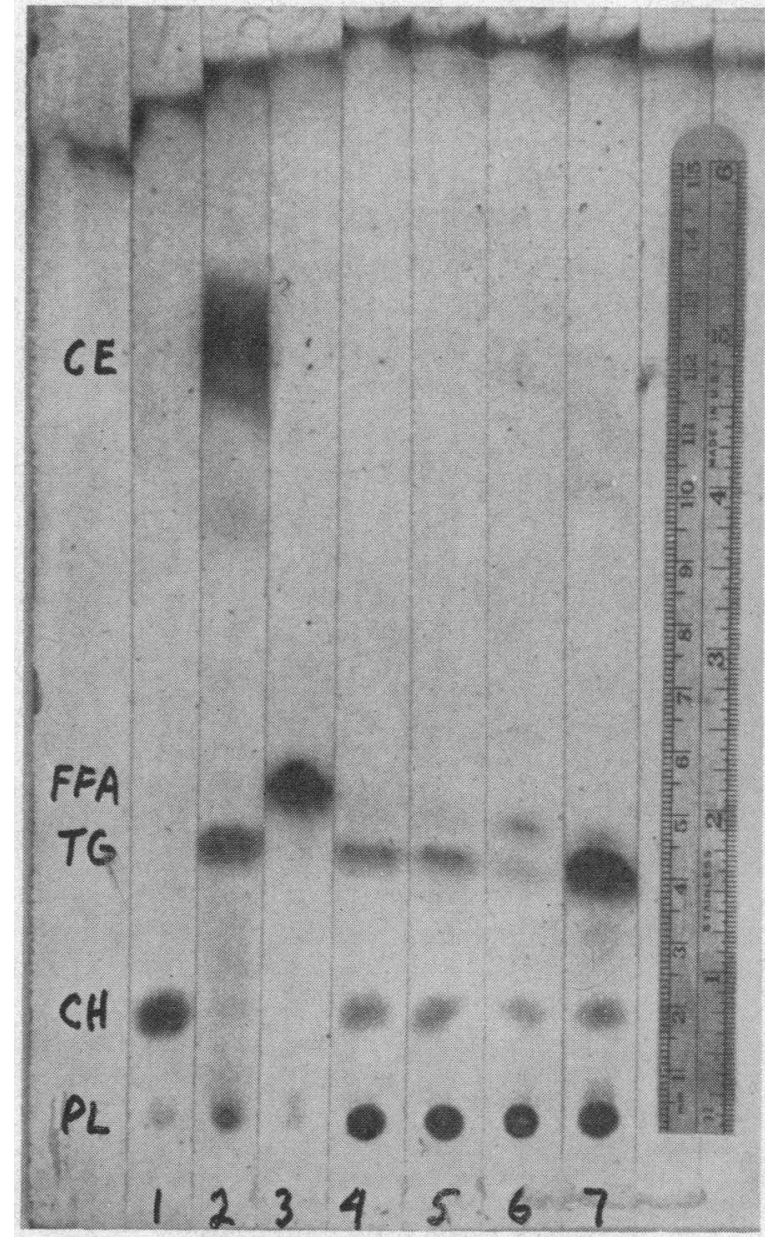

Fig. 1. Thin layer chromatogram of fasting muCOSAL BIOPSY LIPID FROM PATIENT 2, HIS BROTHER, AND HIS MOTHER. Both of the latter had normal amounts of triglyceride in their mucosal lipids (Table I). Lane $1=$ free cholesterol; lane $2=$ triglyceride and cholesteryl ester; lane $3=$ free fatty acid; lanes 4 and $5=$ mucosal lipids of mother of Patient 2; lane $6=$ mucosal lipids of brother of Patient 2; lane 7= mucosal lipids of Patient 2. $\mathrm{PL}=$ phospholipid, $\mathrm{CH}=$ free cholesterol, $\mathrm{TG}=$ triglyceride, $\mathrm{CE}=$ cholesteryl ester. The plate was developed in $n$-hexane : diethyl ether : acetic acid $90: 15: 1$ (vol/ vol) and the spots identified by charring with sulfuric acid.

this fraction was 2 to 3.5 times normal, and in absolute amounts (per cent of biopsy wet weight) it was increased 2.5 to 11 times normal. Thin-layer chromatography was confirmatory (Figure 1). Although phospholipids were lower than normal when expressed as per cent of total lipid, they were within the normal range as per cent of biopsy wet weight. The biopsy material from Patient 3 
was lower in total lipid ( $6 \%$ of biopsy wet weight) and triglyceride (42\% of lipid weight) than the material from Patients 1 and 2. However, both these values were $2 \mathrm{SD}$ above the normal mean, and the characteristic morphologic changes were observed.

In these same studies fatty acid analyses were done. In Patient 3 the phospholipid linoleic acid was significantly low, and the triglyceride linoleic acid was $1 \mathrm{SD}$ below the normal mean. In $\mathrm{Pa}$ tient 2 the corresponding values were not significantly abnormal, though below the normal mean. In the phospholipids, stearic acid (18:0) was also lower, and oleic acid (18:1) higher than normal, but in the triglyceride fraction no other consistent changes were apparent. The mucosal phospholipid distribution was determined on mucosal biopsies from two patients (Table I). In both patients the values for lecithin, sphingomyelin, and phosphatidyl serine and ethanolamine combined were within the normal range.

Although the biopsy material from the patients was compared only to normal adult material, the mucosal lipids of the normal brother (age 10 years) of Patient 2, and sister (age 5 years) of $\mathrm{Pa}$ tient 3 did not differ significantly from the normal adult values (Table I).

\section{Dietary studies}

Fat-free formula. Patient 3 was placed on a fat-free formula ( $0.3 \mathrm{~g}$ fat per day) for 34 days. Serial biopsies $(8,14,20,26,34$ days) studied morphologically showed a progressive reduction in the amount of fasting lipophilia within the absorptive cells of the upper third of the villus. This change began in the more basally located cells, and at the end of the 34-day period the lipid particles were only present in the absorptive cells closest to the villus tip (Figure 2, left). At this time there was less total lipid ( $5.6 \%$ of wet weight) and triglyceride (26\% of lipid weight) in the fasting mucosa than in any of the biopsies obtained during ad libitum feeding. The former value was just beyond $1 \mathrm{SD}$ of the normal mean, and the latter at the upper limit of normal (Table II, Patient 3 , diet $\mathrm{B}$ ). The triglyceride and phospholipid fatty acids changed similarly to those of normal

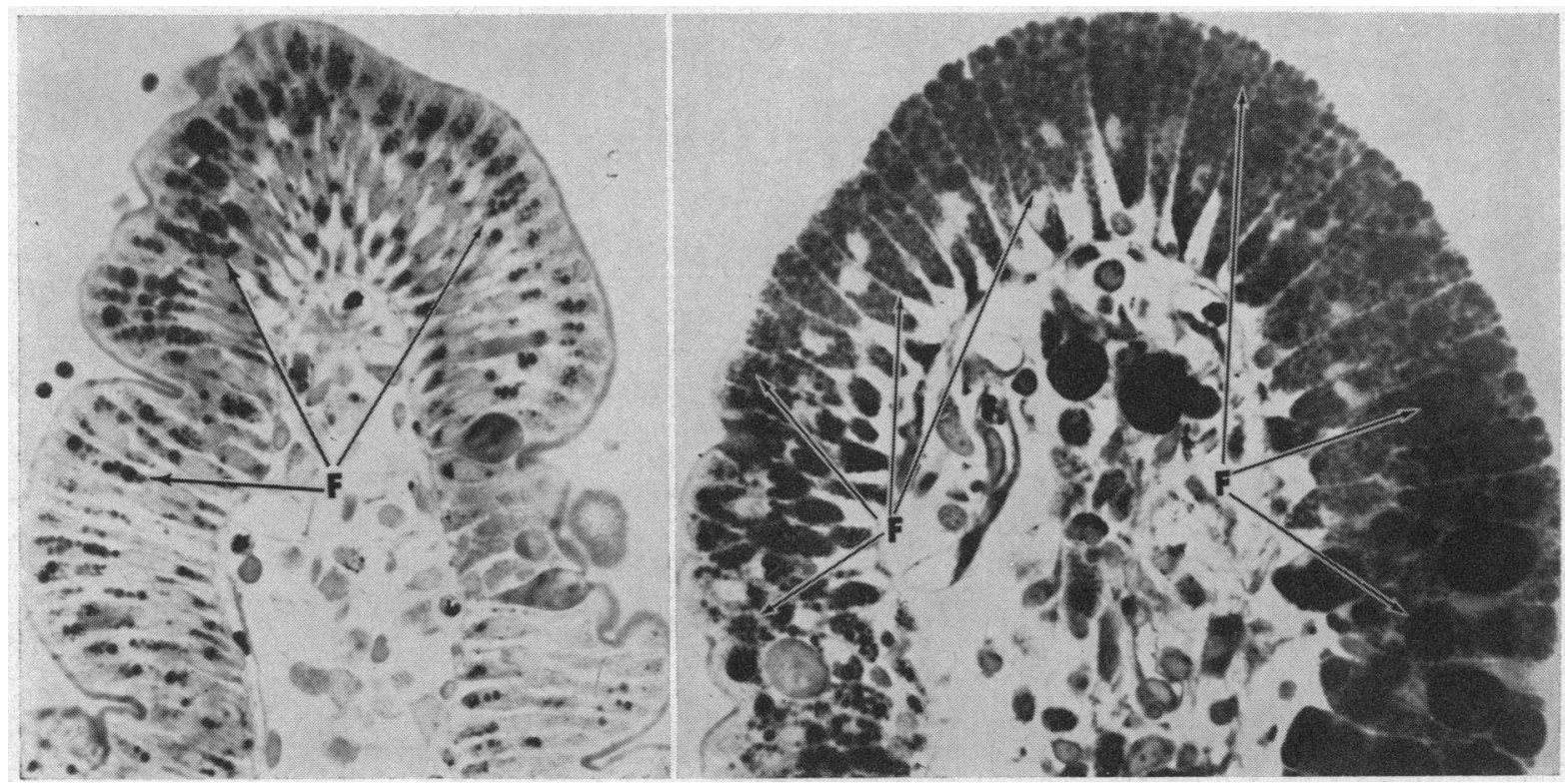

Fig. 2. Left, Tip of proximal Jejunal villus in Patient 3 after an overnight fast following 34 days of a NO-FAT FORMULA. Note the black particulate material that decreases markedly proximal to the extreme villus tip.

Right, Tip of proximal jejunal villus in Patient 3 after an overnight fast 28 days after the first biopsy. The first 17 days of this period, the diet averaged $36.5 \mathrm{~g}$ of fat daily; for the last 11 days it contained an average of $45.0 \mathrm{~g}$ per day (see text). Note that the black particles of lipophilic material engorge most of the absorptive cells and that there is much more of it present than in the biopsy on the left. One micron thick sections, OsO 4 -fixed, epon-embedded, toluidine blue-stained, photographed with blue sensitive Kodalith contact film, magnification $400 \times$. $F=$ fat particles. 
TABLE II

The quantitative and qualitative effects of diet on mucosal lipids in abetalipoproteinemia (Patients 2 and 3)

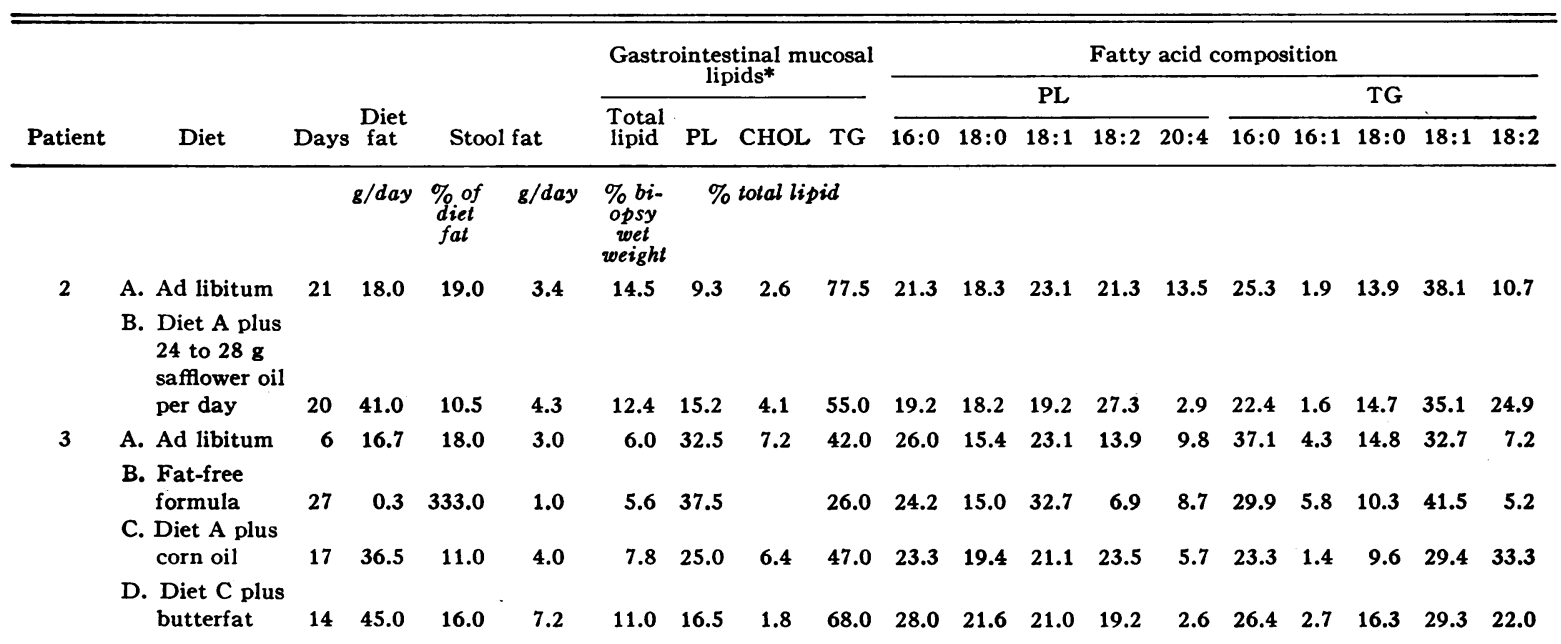

* PL $=$ phospholipid, $\mathrm{CHOL}=$ cholesterol, and $\mathrm{TG}=$ triglyceride

subjects on a no fat diet (11), with a decrease in linoleic acid (18:2) and a rise in oleic acid (18:1) (Table II). During this time fecal fat was actually more than that present in the formula. This was probably due to the fat within the replaceable population of absorptive cells being exfoliated into the gastrointestinal lumen (19), or the production of fatty acids by intestinal microorganisms (20), or both. The correlation between the morphology and the chemical analyses at the end of the period of low fat intake is further evidence that the abnormal lipid increment found during periods of ad libitum feeding was substantially triglyceride.

Added dietary fat. After the no-fat formula diet, Patient 3 was fed a diet averaging $8.5 \mathrm{~g}$ of fat daily supplemented with an average of $28 \mathrm{~g}$ of corn oil daily. After 14 days, the fat content of his fasting mucosal biopsies was increased to $8 \%$, $47 \%$ of which was triglyceride (Figure 2, right; Table II, Patient 3, diet C). The corn oil was then reduced to $20 \mathrm{~g}$ per day, and $17 \mathrm{~g}$ per day (average) of butter fat was added, with an increase in total average daily fat intake to $45 \mathrm{~g}$. Seven days later the total fat content of the fasting mucosal biopsies was increased to $11 \%$ of wet weight, and the triglycerides to $68 \%$ of total lipid. During the first of these two periods of dietary fat supplementation, the patient's coefficient of fat absorption appeared to be better than on the ad libitum diet. In all periods when stool fat was analyzed in this patient, there was a correlation between the absolute amount of fat excreted in the stool per

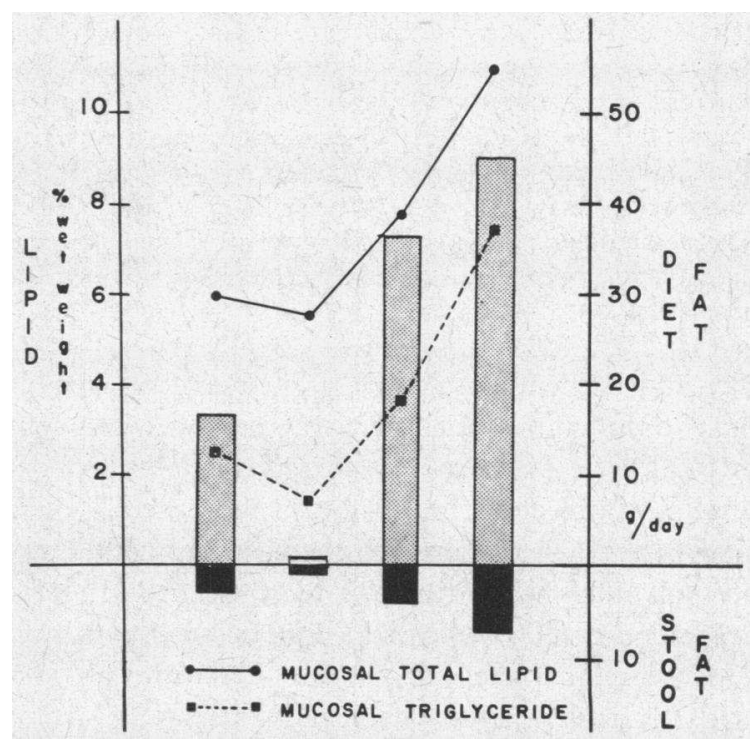

Fig. 3. Correlation of total dietary fat (Shaded BARS), STOOL FAT (SOLID BARS), FASTING TOTAL MUCOSAL LIPID AS PER CENT OF WET BIOPSY WEIGHT (SOLID LINE), AND FASTING MUCOSAL TRIGLYCERIDE AS PER CENT OF WET biopsy Weight (DotTed line) in Patient 3. From left to right the bars and points correspond to dietary regimens $A, B, C$, and $D$ (Table II). The mucosal values represent single analyses at the end of each dietary period. The dietary and stool fat values represent the average of $6,27,17$, and 14 days, respectively. 

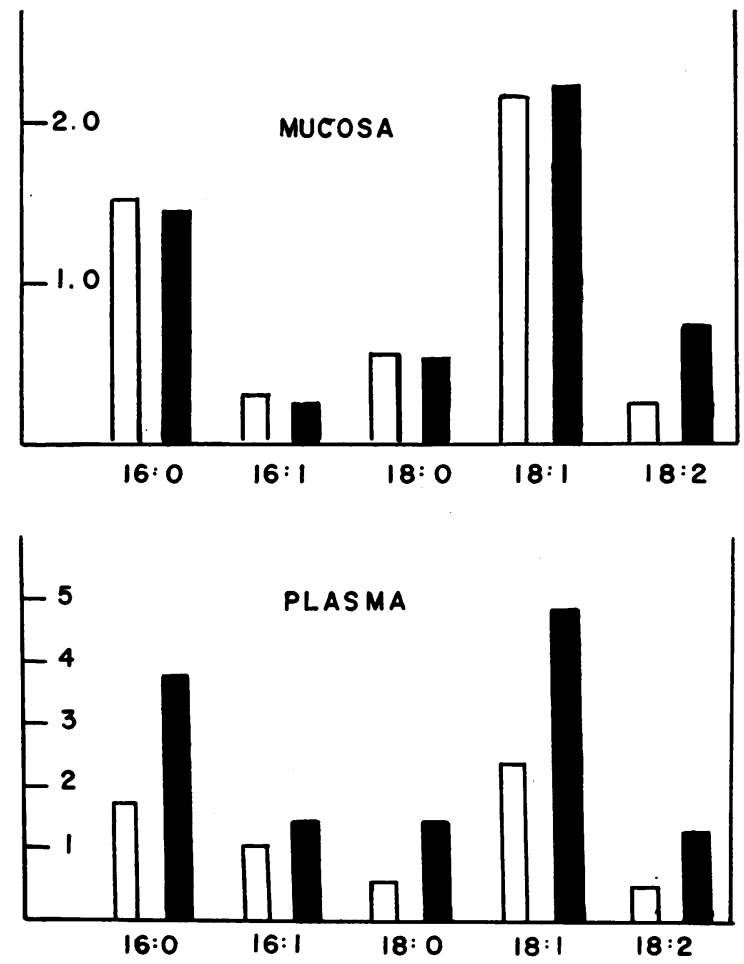

Fig. 4. CoMparison OF THE MUCOSAL AND PLASMa tRIGLYCERIDE FATTY ACID COMPOSITION BEFORE (OPEN BARS) AND AFTER (CLOSED BARS) AN ACUTE CORN OIL LOAD ADministered to Patient 3 after 34 days on a No-fat FORMULA. The postfeeding biopsies were taken at 60 to 76 minutes and combined. The units are micromoles of triglyceride fatty acid per $100 \mathrm{mg}$ biopsy wet weight. The postfeeding plasma was obtained at 95 minutes, and the units are micromoles of triglyceride fatty acid per 100 $\mathrm{ml}$ plasma.

day and both mucosal lipid as per cent of wet biopsy weight and mucosal triglyceride as per cent of total lipid (Figure 3). Triglyceride and phospholipid fatty acids both showed increased linoleic acid $(18: 2)$ in response to the corn oil. This was accompanied by a decrease in oleic $(18: 1)$ and arachidonic (20:4) acids in the phospholipids, and a decrease in oleic $(18: 1)$ and palmitic $(16: 0)$ acids in triglycerides (Table II, Patient 3 ).

The mucosal lipids of Patient 2 were studied after 34 days of ad libitum feeding supplemented with 5 to $45 \mathrm{~g}$ (average $23 \mathrm{~g}$ ) of safflower oil ( $\mathrm{Ta}$ ble II). During this period the triglyceride as per cent of total lipid weight decreased from 78 to $55 \%$ with a reciprocal increase in phospholipid (9 to $15 \%$ ). The changes in fatty acid composition of the major lipid fractions were consistent with the high linoleate content of safflower oil (Table II).

\section{Acute response to fat}

In order to ascertain whether the absorption of fat could be documented when the absorptive cells were depleted of triglyceride, we studied the effect of a single corn oil load in Patient 3 after 34 days of no-fat formula. Biopsies taken 60 to 76 minutes after the intraduodenal instillation of corn oil ( $1.4 \mathrm{ml}$ per $\mathrm{kg}$ ) were not significantly different from the fasting biopsies in total lipid content or the per cent of phospholipid and triglyceride. However, triglyceride linoleic acid (18:2) increased from 5 to 12 moles per 100 moles of fatty acid. Electron micrographs revealed membranebounded lipid droplets within the absorptive cells at the villus tip (17). These lipid particles were identical in appearance to those seen in normal subjects 30 to 45 minutes after fat administration $(15,17,18)$, except that they were all in the smaller range, from 0.1 to $0.5 \mu(17)$. As in normal patients (11), phospholipid fatty acid composition did not change after the corn oil feeding.

In the same experiment we studied plasma lipids at $35,95,185$, and 310 minutes after giving the

TABLE III

The effect of oral fat loads on plasma and lipoprotein triglycerides in Patient 2

\begin{tabular}{|c|c|c|c|c|}
\hline & \multicolumn{2}{|c|}{ Experiment $1 *$} & \multicolumn{2}{|c|}{ Experiment $2^{*}$} \\
\hline & \multicolumn{2}{|c|}{ Fasting after fat } & \multicolumn{2}{|c|}{$\begin{array}{l}5 \text { hours } \\
\text { Fasting after fat }\end{array}$} \\
\hline Fat fed $(g)$ & \multicolumn{2}{|c|}{30} & \multicolumn{2}{|c|}{54} \\
\hline $\begin{array}{l}\text { Total serum triglyceride } \\
\quad(\mathrm{mg} / 100 \mathrm{ml})\end{array}$ & 15 & 26 & 9 & 12 \\
\hline \multicolumn{5}{|c|}{$\begin{array}{l}\text { Serum lipoprotein triglyceride } \\
(\mathrm{mg} / 100 \mathrm{ml} \text { original serum })\end{array}$} \\
\hline$<1.063$ & 2.2 & 2.9 & 1.9 & 2.6 \\
\hline $1.063-1.21$ & 2.8 & 8.3 & 2.1 & 5.1 \\
\hline$>1.21$ & 3.2 & 3.9 & 3.3 & 4.5 \\
\hline \multicolumn{5}{|c|}{ Cholesterol ester fatty acids } \\
\hline $16: 0$ & & & 24 & 27 \\
\hline $16: 1$ & & & 5 & 6 \\
\hline $17: 0$ & & & 4 & \\
\hline $18: 0$ & & & 5 & 3 \\
\hline $18: 1$ & & & 37 & 37 \\
\hline $18: 2$ & & & 23 & 25 \\
\hline \multicolumn{5}{|l|}{ Triglyceride fatty acids } \\
\hline $16: 0$ & & & 28 & 25 \\
\hline $16: 1$ & & & 2 & 6 \\
\hline $17: 0$ & & & 3 & 17 \\
\hline $18: 0$ & & & 27 & 9 \\
\hline $18: 1$ & & & 34 & 34 \\
\hline $18: 2$ & & & 3 & 8 \\
\hline
\end{tabular}

* In experiment 1 the fed fat consisted of $12 \mathrm{~g}$ as cream, $3 \mathrm{~g}$ as milk, and $15 \mathrm{~g}$ as safflower oil. In experiment 2 it was composed of $21 \mathrm{~g}$ as cream, $3.7 \mathrm{~g}$ as milk, $8.5 \mathrm{~g}$ as butter, $15 \mathrm{~g}$ as safflower oil, $5.1 \mathrm{~g}$ as trimargarin, and $1.1 \mathrm{~g}$ as heptadecanoic acid.

The fatty acid data are from the lipoproteins of D 1.063 to 1.210 and are expressed as moles per 100 moles of fatty acid. The "low density lipoprotein" fatty acids showed no significant change. 
corn oil. No visible turbidity was observed. There was no change in cholesteryl ester or phospholipid levels. The triglycerides were $2.2 \mathrm{mg}$ per $100 \mathrm{ml}$ in the fasting specimen and 2.4, 4.4, 2.0 , and $1.8 \mathrm{mg}$ per $100 \mathrm{ml}$ at the respective sampling times, suggesting a rise at 95 minutes. At the same time a significant increase in triglyceride linoleic acid was shown as moles per 100 moles triglyceride fatty acid and as moles per $100 \mathrm{ml}$ plasma. The fatty acids of both mucosal and plasma triglycerides in the fasting state and after corn oil are compared in Figure 4. There was a small decrease in total plasma free fatty acids but no change in their composition.

The effect of fatty loads on plasma lipids was also studied in Patient 2 when he had been on his ad libitum diet for several months. In both experiments, 5 hours after oral ingestion of fat there was an apparent rise in total serum triglyceride; the greatest increment occurred in the 1.063 to 1.21 ultracentrifugal fraction (Table III). When safflower oil was fed, there was a significant increase in total plasma cholesteryl ester linoleic acid from 14 to 21 moles per 100 moles of fatty acid, but sufficient material was not available for analysis of triglyceride fatty acids. In the second experiment heptadecanoic acid was fed as a marker, and significant increments of it were detected only in the high density lipoprotein triglycerides (Table III).

Gastrointestinal mucosal lipids in family members

Fasting biopsy material was obtained from the fathers of Patients 2 and 3 and the mother of $\mathrm{Pa}$ tient 2 as well as a sibling of each of these patients (Table I). There was no significant deviation from normal in any of those analyses for which the patient material was abnormal. Fat balance studies performed on the mother and brother of Patient 2 on ad libitum diets both showed $98 \%$ absorption of dietary fat.

\section{Discussion}

The absorption of dietary triglycerides containing long chain fatty acids is initiated by intraluminar hydrolysis and micelle formation. After translocation into the absorptive cell, the lipid is resynthesized into triglycerides, incorporated into chylomicrons, and in this form discharged into the intestinal lymphatics.

In abetalipoproteinemia over-all absorption is
79 to $90 \%$ of ingested fat on total fat intakes of 13 to $36 \mathrm{~g}$ per day $(2,21$, present study). This malabsorption cannot be attributed to defective digestion of triglyceride within the small bowel lumen. After the intraduodenal instillation of corn oil in Patient 3 serial lipid analyses of his intestinal contents showed a progressive decrease in the amount of triglycerides and an increase in monoglycerides and free fatty acids (Figure 5.) Lamy, Frézal, Polonovski, and Rey found that the hydrolytic activity of a duodenal aspirate tested in vitro was also normal (22). In addition, both pancreatic enzymes $(2,3,21,23)$ and bile acids $(2,21)$ are present in normal concentration.

In abetalipoproteinemia there is also qualitative evidence that the emulsified lipid enters the absorptive cells and is resynthesized into triglyceride, but whether these processes occur at a quantitatively normal rate is not clear from the available data. Isselbacher, Scheig, Plotkin, and Caulfield (4) showed incorporation of palmitate- ${ }^{14} \mathrm{C}$ into mucosal triglyceride, but no data in normal controls were given. In one of our patients an increase in mucosal triglyceride linoleic acid was demonstrated after a corn oil load, but compared with results obtained in normal subjects the change in linoleic acid was not as great and there was no increase in mucosal triglyceride as per cent of total lipid (11).

The available data suggest more convincingly that the defective mechanism is one of those leading directly to, or culminating in, the removal of triglyceride from the absorptive cell. All of our patients had increased fasting mucosal triglyceride on their ad libitum diets. In one patient placed on a fat-poor formula for 34 days this increment was decreased but still remained higher than in normal individuals who had consumed fat-free diets for only 14 days (11). Furthermore, during the absorption of fat in patients with abetalipoproteinemia electron microscopy has not revealed chylomicrons in the intercellular spaces of the absorptive cells or within the lamina propria or lacteals of the villus cores $(17,24)$. Distension of the Golgi vacuoles with lipophilic material in response to fat feeding (17), and the small particles, apparently lipoproteins (25), normally seen between the bases of the absorptive cells even during the fasting state (18), are not found in abetalipoproteinemia (17). Finally, postprandially or after a fatty meal there is no chylomicronemia $(2,21$, present study); 


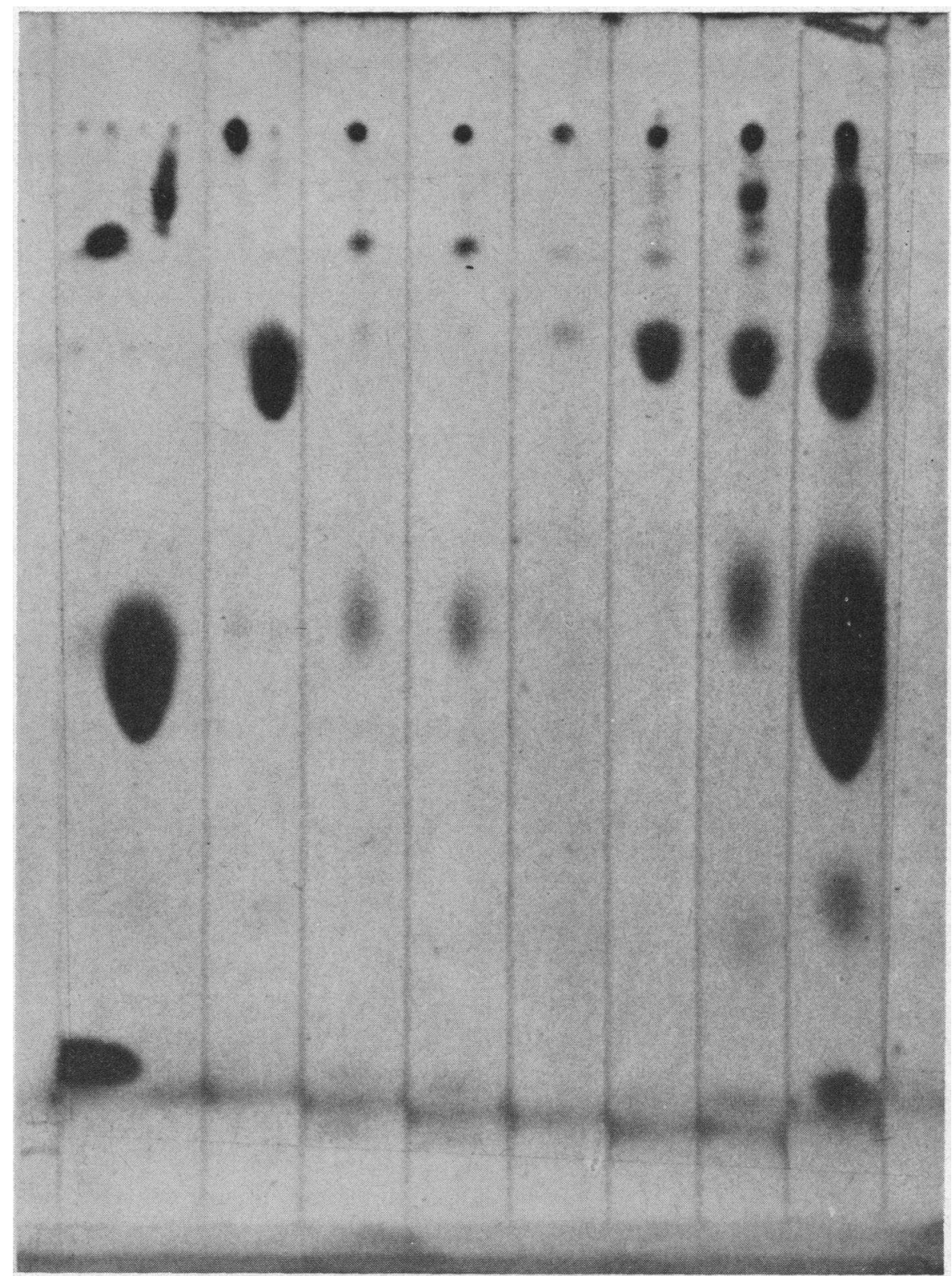

Fig. 5. THIN LAYER Chromatograph OF DUODENAL CONTENTS AND MUCOSAL LIPIDS AFTER ADMinistration of CORN OIL intraduodenally to Patient 3. Lanes 1 to $4=$ duodenal contents $0.5,1,2$, and 3 hours after fat administration, respectively. Lane $5=$ lipids of fasting mucosa. Lane $6=$ lipids of mucosa 1 hour after fat. Lane $7=$ standard monoglyceride (right) and free fatty acid (left). Lane $8=$ standard diglyceride (left), free cholesterol (right center), triglyceride (left center), and cholesteryl ester (right). The development and localization of spots were as for Figure 1.

increments in the total plasma triglyceride are minimal if found at all ${ }^{5}$ and may not be significant.

5 These findings suggest that chylomicrons are not formed in significant quantity, although their excessively rapid removal could mask any significant influx from lymph.
Although this study and the experiments of others have not precisely elucidated the defect in triglyceride absorption, they raise two interesting questions: 1) By what route is fat absorbed in abetalipoproteinemia? 2) How is the malabsorption related to the absence of beta lipoprotein? 
A reasonable answer to the first question is that the absorbed lipid may enter through the portal vein as free fatty acids (26) to be subsequently incorporated into triglyceride by the liver. Some support for this concept was obtained by Ahrens, Novikoff, and Spritz (24), who demonstrated that corn oil linoleic acid given orally to a patient with abetalipoproteinemia after 2 weeks on a fat-free diet appeared in the plasma as free fatty acid and later in esterified form. Fatty infiltration was noted in the liver of one patient (4). This change, if portal absorption is significant, might be attributed to an influx of dietary fatty acid, via the portal vein, in excess of that which could be removed from the liver by the abnormal (27) high density lipoproteins.

The second question was initially studied by Rey, who hypothesized that the absorptive defect in this disease is secondary to the absence of low density lipoproteins (21). He raised the plasma low density lipoprotein concentration of a patient to $65 \%$ of normal by exchange transfusion. However, after oral fat demonstrable chylomicronemia or increased total plasma triglycerides were still not found. Although this result suggested that low density lipoproteins may not play an essential role in triglyceride absorption, another interpretation is that they were not present long enough to activate dormant enzyme systems. Alternatively, perhaps intracellular beta lipoprotein is necessary for the packaging, intracellular transport, or discharge of chylomicrons. If so, such an acute experiment might not have allowed sufficient accumulation of the lipoprotein intracellularly. $\mathrm{Pa}$ tients with Tangier disease, in whom high density lipoproteins are absent, do form chylomicrons after oral ingestion of fat. ${ }^{6}$ Since in abetalipoproteinemia chylomicrons are apparently not secreted in normal fashion, the presence of low density lipoproteins would a priori seem more essential to chylomicron formation than, as previously supposed, high density lipoprotein (29).

The work of Sabesin and Isselbacher suggests that the intestinal absorptive cell in abetalipoproteinemia may not synthesize the protein coat necessary for the formation of chylomicrons. After administration of puromycin to rats, these animals

6 Although chylomicrons are demonstrable postprandially in Tangier disease, their lipid composition is abnormal, principally in a deficiency of free cholesterol and cholesteryl ester (28). developed a progressive fall in their serum triglycerides and numerous vacuoles in their absorptive cells similar to those seen in abetalipoproteinemia (30). However, absence of chylomicrons in the intercellular spaces, villus cores, and lacteals, and the absence of "lipoprotein particles" in the intercellular spaces were not recorded. One implication of these studies might be that chylomicrons are necessary for low density lipoprotein formation, another that the same protein moiety is essential for both.

As in other hereditary metabolic disorders, the parents and siblings of these patients with abetalipoproteinemia have been studied. To date, none of the clinical or laboratory abnormalities observed in the patients (malabsorption, retinal degeneration, neurologic disease, plasma lipids, plasma lipoproteins, or red cell lipids) have been found in apparently normal family members. ${ }^{7}$ Our studies of the gastrointestinal mucosal lipids in five family members have been equally fruitless. Despite abundant conjecture to the contrary, it may evolve that the abnormalities presently under study are biochemically distant from the basic defect.

\section{Acknowledgments}

We wish to thank Miss Tamara Sheik for her expert assistance in preparing the morphologic sections and Mrs. Dolores Dong, Miss Mildred Medick, Miss Susan Palmer, and Miss Bonnie Sinnott for their able technical assistance. Dr. William O. Dobbins III assisted in the planning and execution of certain of the experiments on patient J.G. We are most grateful to Dr. Angelo DiGeorge, Philadelphia, $\mathrm{Pa}$., for allowing us to biopsy his patient, and to Drs. William Deamer and Lloyd Brandborg for referring Patient 3 to us and for their continued interest in our studies.

\section{Addendum}

We have recently rebiopsied the duodenal mucosa of Patient 3 ; by allowing the tube to advance we also obtained a sample from the proximal ileum. Although the duodenal mucosa was characteristically engorged with lipophilic material, the ileal biopsy was virtually normal in appearance.

\section{Appendix 1}

Patient 2 (M.S.), born in 1954, was initially described in 1963 (8). This report reviews his progress to January 1966, age 12 years. Growth proceeded slowly and

7 With the exception of the case reported by Salt and associates (2) in which the parents had half the normal levels of beta lipoprotein. 
in January 1966 he weighed 65 pounds and was $54 \frac{1}{3}$ inches tall, the third percentile for both height and weight. However, intelligence continued above average, and scholastic progress was satisfactory. A low fat diet was continued to avoid abdominal discomfort and diarrhea. He was urged to take supplements of unsaturated fatty acids ( 5 to $10 \mathrm{~g}$ of corn or safflower oil daily), but low levels of linoleic acid in serum lipids and adipose tissue (less than $4 \%$ ) make the regularity of this intake questionable.

Neurologic examination in January $1966^{\circ}$ revealed absent deep tendon reflexes except for minimal triceps responses; flexor plantar responses; impaired vibration and position sense; poorly executed tandem walking; normal perception of pin prick, light touch, and temperature; slightly clumsy rapid finger movements; and mild bilateral impairment of heel to knee to shin movements. The exotropia in the left eye was absent, having been surgically corrected. Funduscopic examination, visual field testing, and dark adaptometry over a 39-minute period were all normal.

The high percentage of abnormal erythrocytes (acanthocytes) persisted in the blood, although the leukocytes and platelets remained normal morphologically. Autohemolysis of defibrinated whole blood $\left(37^{\circ}, 48\right.$ hours) without additives remained consistently elevated (15 to $90 \%$ ) until tocopherol supplementation was begun (31). This resulted in normal, or almost normal, autohemolysis values, a rise in hematocrit from levels of 34 and 35 to 37 and $38 \%$ without change in reticulocyte counts, which averaged about $1 \%$. Serum total cholesterol, phospholipid, and triglyceride did not change. Vitamin A levels rose to $46 \mathrm{IU}$ per $100 \mathrm{ml}$ as a result of daily supplementation.

\section{Appendix 2}

Patient 3 (J.G.), a male born in May 1957, was referred to us. ${ }^{9} \mathrm{He}$ is the fourth of five children. The diagnosis of abetalipoproteinemia was established by the referring physicians on the basis of a serum cholesterol of $30 \mathrm{mg}$ per $100 \mathrm{ml}$, a characteristic gastrointestinal biopsy, failure to demonstrate beta lipoprotein by immunoelectrophoresis, and a compatible clinical picture. The following information is a compilation of the studies we have done as well as the clinical history and laboratory data obtained before the patient was referred to us.

Growth, development, and mental ability. The patient weighed 6 pounds 13 ounces at birth and was noted to have a "large abdomen" and very thin legs. Symptoms of malabsorption were present soon after birth (see below), and he has remained well below the usual norms for height and weight. He sat at 7 months, stood at $9 \frac{1}{2}$ months, walked at 14 months, and talked as early as his four normal siblings. A bone survey at 7 years of age

${ }^{8}$ Dr. William Haas, New York University Medical Center.

9 Drs. Lloyd Brandborg and William Deamer, San Francisco, Calif. revealed an average bone age of $5 \frac{1}{2}$ years. Between June 1964 and December 1965 when his diet was severely restricted in fat and he took supplements of corn oil (5 to $15 \mathrm{ml}$ per day), his height increased from 108 to $113 \mathrm{~cm}$ (normal slope, but both within the third percentile) and his weight from $17 \mathrm{~kg}$ (third percentile) to $22 \mathrm{~kg}$ (tenth percentile). His physical activities were normal for a child his age. Mental status was not assessed objectively, but he seemed intelligent and performed well in the first and second grades.

Neurologic, ophthalmologic, and musculoskeletal status. The patient has allegedly always run as fast as other children his size and has had no difficulties with balance. $\mathrm{He}$ has had no known visual difficulties, squint, or other eye disease. All ophthalmologic examinations have been normal, including the fundi. The most recent of these was in February 1966. The neurological findings did not change between June 1964 and January 1966. There was complete absence of deep tendon reflexes, absence of vibratory sense to approximately the midthoracic spine, and decreased vibratory sense in the hands. He was unable to walk a straight line (one foot in front of the other) without losing his balance. Manual evaluation of muscle strength revealed slight generalized weakness. Urinary creatine ranged between 190 and $304 \mathrm{mg}$ per 24 hours and urinary creatinine between 304 and $455 \mathrm{mg}$ per 24 hours. On one occasion intramuscular administration of $100 \mathrm{mg}$ vitamin $\mathrm{E}$ did not affect the urinary creatinine excretion for the next 3 days. Electroencephalogram and electromyography (right gastrocnemius, right anterior tibial, and right quadriceps) were normal. Nerve conduction (right median, right ulnar, right peroneal) was also within normal limits (48 to 51 meters per second).

Gastrointestinal disease. From infancy until June 1964 with rare remissions, the patient was bothered by frequent, bulky, and foul-smelling stools. In infancy, formulas with a meat, goat's milk, or soybean base, used as milk substitutes, failed to ameliorate the diarrhea. During the second and third years of life dietary fat was gradually eliminated. The exclusion of wheat from the diet at various times was not associated with any clear improvement. In February 1964 (University of California Hospital) barium enema, small bowel series, and sweat chlorides were normal. Trypsin was present in a $1 / 100$ dilution of duodenal aspirate (X-ray film test), and $29 \%$ of a xylose load was excreted after 5 hours. No ova or parasites were found in the stool. Small bowel biopsy at that time revealed the morphologic change characteristic of abetalipoproteinemia (Dr. Brandborg). A small bowel series at the University of Washington in June 1964 suggested widening of the small bowel loops and coarsening of the mucosal folds. Since August 1964 the patient has been maintained on a diet as low in fat as could conveniently be fed in the home (approximately 5 to $15 \mathrm{~g}$ of fat daily). On this regimen with supplements of corn oil ( 5 to $15 \mathrm{ml}$ daily) he has had one to two formed bowel movements a day and has been essentially asymptomatic with respect to his gastrointestinal symptoms. The results of fat balance studies and analysis of 
his gastrointestinal mucosa by morphologic and chemical techniques are described in the body of this report. In the summer of 1964 without vitamin supplements, his serum carotene was $10 \mu \mathrm{g}$ per $100 \mathrm{ml}$ (normal 20 to $100 \mu \mathrm{g}$ per $100 \mathrm{ml}$ ). Plasma tocopherol was undetectable in February 1965 (Dr. Kayden).

Hematologic disease. At 5 weeks of age the patient had a macrocytic anemia with hemoglobin of $9.0 \mathrm{~g}$. Folic acid therapy apparently resulted in a normal blood count, and his family was not aware of anemia subsequently. On his initial admission to the University of Washington Hospital in June 1964, his hematocrit was 39 with a hemoglobin of 12.8 , but the reticulocyte count ranged from 4.5 to 7.0. Mean corpuscular volume was 94 , mean corpuscular hemoglobin, 31, mean corpuscular hemoglobin concentration, 33. Peripheral blood smear showed numerous acanthocytes; platelets and leukocytes appeared morphologically normal, and the platelet count was 465,000 . Corrected sedimentation rate was $1 \mathrm{~mm}$ per hour. Bone marrow aspiration (August 1964) revealed normal cellularity and a normal erythroid/myeloid ratio. No morphologic abnormalities of the red cell precursors were noted; bone marrow iron stores were adequate. Autohemolysis of whole defibrinated blood without additives incubated at $37^{\circ}$ for 48 hours ranged from 20 to $80 \%$ (seven separate determinations). As in previous patients, this was corrected by small additions of normal serum and by glucose (32). Red cell lipids, studied on numerous occasions, showed the same abnormalities seen in other patients with this disease : greater than normal amounts of sphingomyelin and decreased quantities of lecithin and esterified linoleic acid (8). The red cell phospholipid distribution was not affected by the low fat diet or therapy with corn oil. The linoleic acid esterified to total red cell phospholipid was $2.7 \%$ on the first observation, dropped to $0.8 \%$ on the no fat formula, and rose to $4.2 \%$ after 7 weeks on corn oil. It was still the same after 6 months on corn oil ( 5 to $10 \mathrm{ml}$ per day). Unless given supplementary vitamin $\mathrm{K}$ the patient's prothrombin time has been prolonged (20 to 24 seconds), but it returned to virtually normal levels on oral or parenteral vitamin $\mathrm{K}$.

Endocrinology studies (summer 1964). Basal metabolic rate was plus 7 ; urinary 17 -ketosteroids, 1.0 and 1.3 mg per 24 hours; urinary 17 -ketogenic steroids, 3.0 and $2.7 \mathrm{mg}$ per 24 hours (all values normal for this laboratory). Plasma cortisol rose normally after the parenteral administration of ACTH.

Plasma lipids and lipoproteins. In June 1964 the patient's serum cholesterol was $40 \mathrm{mg}$ per $100 \mathrm{ml}$; lipid phosphorus, $2.3 \mathrm{mg}$ per $100 \mathrm{ml}$, and triglycerides, $2 \mathrm{mg}$ per $100 \mathrm{ml}$. No beta-lipoprotein was detected by immunoelectrophoresis. Ultracentrifugal analysis of the patient's serum revealed almost complete absence of the lipoproteins of density less than 1.063, a normal level of plasma lipoproteins floating between the densities of 1.063 and 1.110 , and low levels of the high density lipoproteins floating between the densities of 1.110 and 1.21 . These are the same abnormalities that have been seen in other patients (27) and will be reported in greater detail elsewhere.
Family studies. The patient's father, mother, three older siblings, and one younger sibling are all normal by history, particularly with respect to malabsorption and ophthalmologic, neurologic, or hematologic defects. The mother, father, and younger sister have been studied. The morphologic and chemical studies of their gastrointestinal biopsies are in Results. In addition, their plasma lipoproteins (by ultracentrifugation), plasma lipids including phospholipid distribution, red cell lipids, and autohemolysis were all within normal limits.

\section{References}

1. Singer, K., B. Fisher, and M. A. Perlstein. Acanthrocytosis: a genetic erythrocytic malformation. Blood 1952, 7, 577.

2. Salt, H. G., O. H. Wolff, J. K. Lloyd, A. S. Fosbrooke, A. H. Cameron, and D. V. Hubble. On having no beta-lipoprotein, a syndrome comprising A-beta-lipoproteinaemia, acanthocytosis, and steatorrhoea. J.-Lancet 1960, 2, 325.

3. Schwartz, J. F., L. P. Rowland, H. Eder, P. A. Marks, E. F. Osserman, E. Hirschberg, and H. Anderson. The Bassen-Kornzweig syndrome: deficiency of serum $\beta$-lipoprotein. Arch. Neurol. (Chic.) 1963, 8, 438.

4. Isselbacher, K. J., R. Scheig, G. R. Plotkin, and J. B. Caulfield. Congenital $\beta$-lipoprotein deficiency: an hereditary disorder involving a defect in the absorption and transport of lipids. Medicine (Baltimore) $1964,43,347$.

5. Mabry, C. C., A. M. DiGeorge, and V. H. Auerbach. Studies concerning the defect in a patient with acanthrocytosis (abstract). Clin. Res. 1960, 8, 371.

6. Ways, P., and C. Parmentier. G.I. Mucosal lipids in acanthocytosis (abstract). Clin. Res. 1963, 11, 77.

7. Di George, A. M., C. C. Mabry, and V. H. Auerbach. A specific disorder of lipid transport (acanthrocytosis): treatment with intravenous lipids (abstract). Amer. J. Dis. Child. 1961, 102, 580.

8. Ways, P., C. F. Reed, and D. J. Hanahan. Red-cell and plasma lipids in acanthocytosis. J. clin. Invest. $1963,42,1248$.

9. Watt, B. K., and A. Merrill. Composition of foods. Handbook number 8, U. S. Department of Agriculture, 2nd ed., 1963.

10. Van De Kamer, J. H., H. ten B. Huinink, and H. A. Weyers. Rapid method for the determination of fat in feces. J. biol. Chem. 1949, 177, 347.

11. Saunders, D. R., P. Ways, C. Parmentier, and C. E. Rubin. Studies on the lipid composition of human duodenal mucosa. J. clin. Invest. 1966, 45, 1516.

12. Ways, P., and D. J. Hanahan. Characterization and quantification of red cell lipids in normal man. J. Lipid Res. 1964, 5, 318.

13. Crowley, J., P. Ways, and J. W. Jones. Human fetal erythrocyte and plasma lipids. J. clin. Invest. 1965, 44, 989. 
14. Leveille, G. A., J. W. Schockley, and H. E. Sauberlich. The Influence of Cholesterol on the Determination of Serum Glycerides. Report 255, U. S. Army Medical Research and Nutrition Laboratory, 1961.

15. Phelps, P. C., C. E. Rubin, and J. H. Luft. Electron microscope techniques for studying absorption of fat in man with some observations on pinocytosis. Gastroenterology 1964, 46, 134.

16. Parmentier, C. M. Histologic demonstration of intestinal fat absorption in man with an improved carbowax technique. Gastroenterology 1962, 43, 1.

17. Dobbins, W. O. III. An ultrastructural study of the intestinal mucosa in congenital $\beta$-lipoprotein deficiency with particular emphasis upon the intestinal absorptive cell. Gastroenterology 1966, 50, 195.

18. Rubin, C. E. Electron microscopic studies of triglyceride absorption in man. Gastroenterology 1966, 50, 65.

19. Sperry, W. M. Lipid excretion. VIII. The lipid content of the intestinal mucosa. J. biol. Chem. 1932, 96, 759.

20. Sperry, W. M. Lipid excretion. V. A study of the partition of the fecal lipids with special reference to bacteria. J. biol. Chem. 1929, 81, 299.

21. Rey, J. L'absence Congénitale de Beta-lipoprotéines. Thèse. Paris, R. Foulon, 1961.

22. Lamy, M., J. Frézal, J. Polonovski, and J. Rey. L'absence congénitale de beta-lipoprotéines. Presse méd. 1961, 69, 1511.

23. Friedman, I, S., H. Cohn, M. Zymaris, and M. G. Goldner. Hypocholesteremia in idiopathic steatorrhea. Arch. intern. Med. 1960, 105, 112.
24. Ahrens, E. H., Jr., A. Novikoff, and N. Spritz. Personal communication, 1962.

25. Casley-Smith, J. R. The identification of chylomicra and lipoproteins in tissue sections and their passage into jejunal lacteals. J. Cell Biol. 1962, 15, 259.

26. Dawson, A. M., N. Gallagher, D. R. Saunders, and J. Webb. Resynthesis and transport of long chain fatty acids by the small gut in Metabolism and Physiological Significance of Lipids, R. M. C. Dawson and D. N. Rhodes, Eds. New York, Wiley and Sons, 1964, p. 243.

27. Jones, J. W., and P. Ways. Abnormalities of high density lipoprotein in A-beta lipoproteinemia (acanthocytosis) (abstract). Clin. Res. 1965, 13, 325.

28. Fredrickson, D. S. Familial high-density lipoprotein deficiency: Tangier disease in The Metabolic Basis of Inherited Disease, 2nd ed., J. B. Stanbury, J. B. Wyngaarden, and D. S. Fredrickson, Eds. New York, McGraw-Hill, 1966, p. 486.

29. Rodbell, M., and D. S. Fredrickson. The nature of the proteins associated with dog and human chylomicrons. J. biol. Chem. 1959, 234, 562.

30. Sabesin, S. M., and K. J. Isselbacher. Protein synthesis inhibition: mechanism for the production of impaired fat absorption. Science 1965, 147, 1149.

31. Kayden, H. J., and R. Silber. The role of vitamin $\mathrm{E}$ deficiency in the abnormal autohemolysis of acanthocytosis. Trans. Ass. Amer. Phycns 1965, 78, 334.

32. Simon, E. R., and P. Ways. Incubation hemolysis and red cell metabolism in acanthocytosis. J. clin. Invest. 1964, 43, 1311. 